Atmos. Chem. Phys., 17, 12121-12131, 2017

https://doi.org/10.5194/acp-17-12121-2017

(C) Author(s) 2017. This work is distributed under

the Creative Commons Attribution 3.0 License.

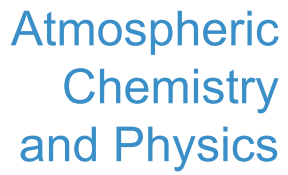

(c) (i)

\title{
Oscillations in atmospheric water above Switzerland
}

\author{
Klemens Hocke $^{1,2}$, Francisco Navas-Guzmán ${ }^{1}$, Lorena Moreira ${ }^{1}$, Leonie Bernet ${ }^{1,2}$, and Christian Mätzler ${ }^{1,2}$ \\ ${ }^{1}$ Institute of Applied Physics, University of Bern, Bern, Switzerland \\ ${ }^{2}$ Oeschger Centre for Climate Change Research, University of Bern, Bern, Switzerland
}

Correspondence to: Klemens Hocke (klemens.hocke@iap.unibe.ch)

Received: 22 March 2017 - Discussion started: 17 May 2017

Revised: 13 July 2017 - Accepted: 13 September 2017 - Published: 12 October 2017

\begin{abstract}
Cloud fraction (CF), integrated liquid water (ILW) and integrated water vapour (IWV) were continuously measured from 2004 to 2016 by the TROpospheric WAter RAdiometer (TROWARA) in Bern, Switzerland. There are indications for interannual variations of CF and ILW. A spectral analysis shows that IWV is dominated by an annual oscillation, leading to an IWV maximum of $24 \mathrm{~kg} \mathrm{~m}^{-2}$ in July to August and a minimum of $8 \mathrm{~kg} \mathrm{~m}^{-2}$ in February. The seasonal behaviour of CF and ILW is composed by both the annual and the semiannual oscillation. However, the annual oscillation of CF has a maximum in December while the annual oscillation of ILW has a maximum in July. The semiannual oscillations of CF and ILW are strong from 2010 to 2014. The normalized power spectra of ILW and CF show statistically significant spectral components with periods of 76 , 85,97 and 150 days. We find a similarity between the power spectra of ILW and CF with those of zonal wind at $830 \mathrm{hPa}$ $(1.5 \mathrm{~km})$ above Bern. Particularly, the occurrence of higher harmonics in the CF and ILW spectra is possibly forced by the behaviour of the lower-tropospheric wind. The mean amplitude spectra of CF, ILW and IWV show increased shortterm variability on timescales less than 40 days from spring to fall. We find a weekly cycle of CF and ILW from June to September with increased values on Saturday, Sunday and Monday.
\end{abstract}

\section{Introduction}

Observation and characterization of the oscillations of atmospheric water lead to a better understanding of the cloud processes, the cloud-induced changes in the Earth radiative fluxes and the water cycle. In this study, we investigate the oscillations in 12-year time series of cloud fraction (CF), integrated liquid water (ILW) and integrated water vapour (IWV) above Bern, Switzerland. The combined spectral analysis of atmospheric water parameters can give hints about cloud formation and transport processes. The seasonal cycle of the atmospheric water parameter $\mathrm{CF}$ at midlatitudes has only been described in a few articles, while the seasonal cycle in ILW remains undescribed as of now. The climatology of IWV at Bern was presented by Morland et al. (2009), showing an annual oscillation (AO) with a summer maximum of about $22 \mathrm{~kg} \mathrm{~m}^{-2}$ and a winter minimum of about $8 \mathrm{~kg} \mathrm{~m}^{-2}$. This simple seasonal cycle in IWV is a consequence of the Clausius-Clapeyron equation and the seasonal cycle of air temperature at midlatitudes.

Cossu et al. (2015) presented a 10-year cloud fraction climatology of liquid water clouds over Bern observed by the TROpospheric WAter RAdiometer (TROWARA). CF had a maximum of $60.9 \%$ in winter and a minimum of $42.0 \%$ in summer. They did not discuss the indication of a semiannual oscillation (SAO) in the seasonal cycle of CF. Hocke et al. (2016) divided the liquid water clouds into three classes, thin clouds, supercooled thick clouds and warm thick clouds, using the TROWARA data set at Bern. The warm thick clouds showed a CF maximum of $30 \%$ in the summer months and a minimum of $6 \%$ in winter. The CF of supercooled thick clouds was maximal in winter (29\%) and minimal in summer $(2 \%)$. Thin clouds had a fairly constant CF ranging from $30 \%$ in winter to $24 \%$ in summer. Massons et al. (1998) derived the seasonal cycle of cloud fraction using Meteosat images. CF was about $50 \%$ over the Iberian peninsula during winter and about $30 \%$ in summer

Compared to these few articles about the seasonal cycle of $\mathrm{CF}$ at midlatitudes, there are more articles about the seasonal change of CF over Antarctica, Arctic and the tropics. Meehl et al. (1998) described the mechanism of a SAO in sea 

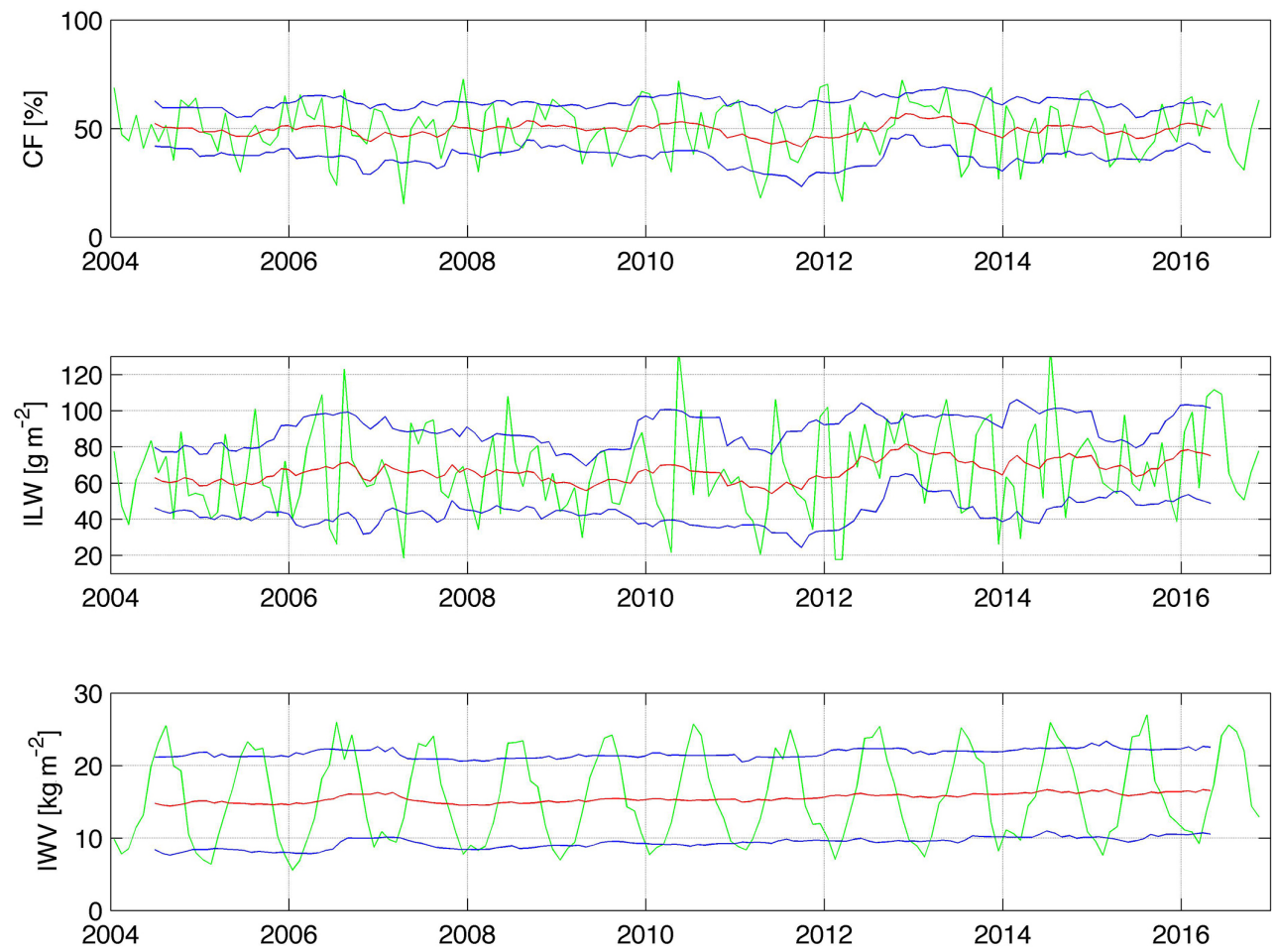

Figure 1. Time series of CF, ILW and IWV at Bern. The monthly means are given by the green lines while the red lines denote the annual means (12-month sliding average with a step of 1 month). The blue lines shows the standard deviations of the annual means.

level pressure in the Southern Hemisphere which arises from different responses to the surface heat budget over the polar continent and the midlatitude ocean. Van den Broeke (2000) investigated a possible relation between the SAO, the nearsurface wind and cloudiness. He found only at the Antarctic stations Halley and Faraday a firmly established halfyearly wave in the mean annual cycles of wind speed and cloudiness. Bromwich et al. (2012) gave a review about tropospheric clouds in Antarctica. One focus was on the seasonal and interannual variability of cloud amounts. Over the Southern Ocean equatorward of $60^{\circ} \mathrm{S}$, only CloudSat and CALIPSO showed a minimum in cloudiness occurring in summer (5\% lower than in winter). Verlinden et al. (2011) suggested that this summertime minimum is consistent with the seasonality of the extratropical cyclone activity.

Over the Arctic ocean, Beesley and Moritz (1999) compared observations and simulations of the seasonal cycle of the total cloud amount. The observed seasonal cycle of $\mathrm{CF}$ is from $60 \%$ in winter to $85 \%$ in summer while the simulated seasonal cycle goes from $65 \%$ in winter to $75 \%$ in summer (if the simulation includes ice microphysics). The results of Beesley and Moritz (1999) suggest that the duration of the summertime cloudy season over the Arctic Ocean would be longer in a warmer climate and shorter in a cooler climate. The influence of wind speed on shallow marine cumulus convection was investigated by Nuijens and Stevens
(2012). Their model simulations showed that an increase in the trade winds leads to a deepening of the cloud layer.

For health and environmental reasons, the weekly cycle of aerosol concentration and precipitation is of high interest. Stjern (2011) detected weekly cycles in the $\mathrm{SO}_{2}$ and $\mathrm{NO}_{2}$ concentrations in the polluted region of the black triangle of Czech Republic, Germany and Poland. The weekly cycles of the $\mathrm{SO}_{2}$ and $\mathrm{NO}_{2}$ concentrations have decreased values at the weekend and increased values in the midweek. The microphysical effect of the aerosol concentration on the formation and the size of cloud droplets may induce weekly cycles in cloud parameters and precipitation. Another cause could be that the amount of aerosol concentration triggers surface diabatic heating and convective motions (Gong et al., 2007). Stjern (2011) found that weekly cycles of cloud amount and the frequency of light precipitation events above the Czech Republic are dominated by midweek decreases and weekend maxima.

Our study extends the research on oscillations in atmospheric water by analysing the continuous measurements of TROWARA in Bern, Switzerland. In Sect. 2, we describe the ground-based microwave radiometer TROWARA, its data set and the data analysis methods which we use in this study. Section 3 presents the seasonal cycles, the power spectra, and the bandpass-filtered annual and semiannual oscillations in CF, ILW and IWV. Inspired by the study of Nuijens and Stevens (2012), we look at the seasonal cycle and power 

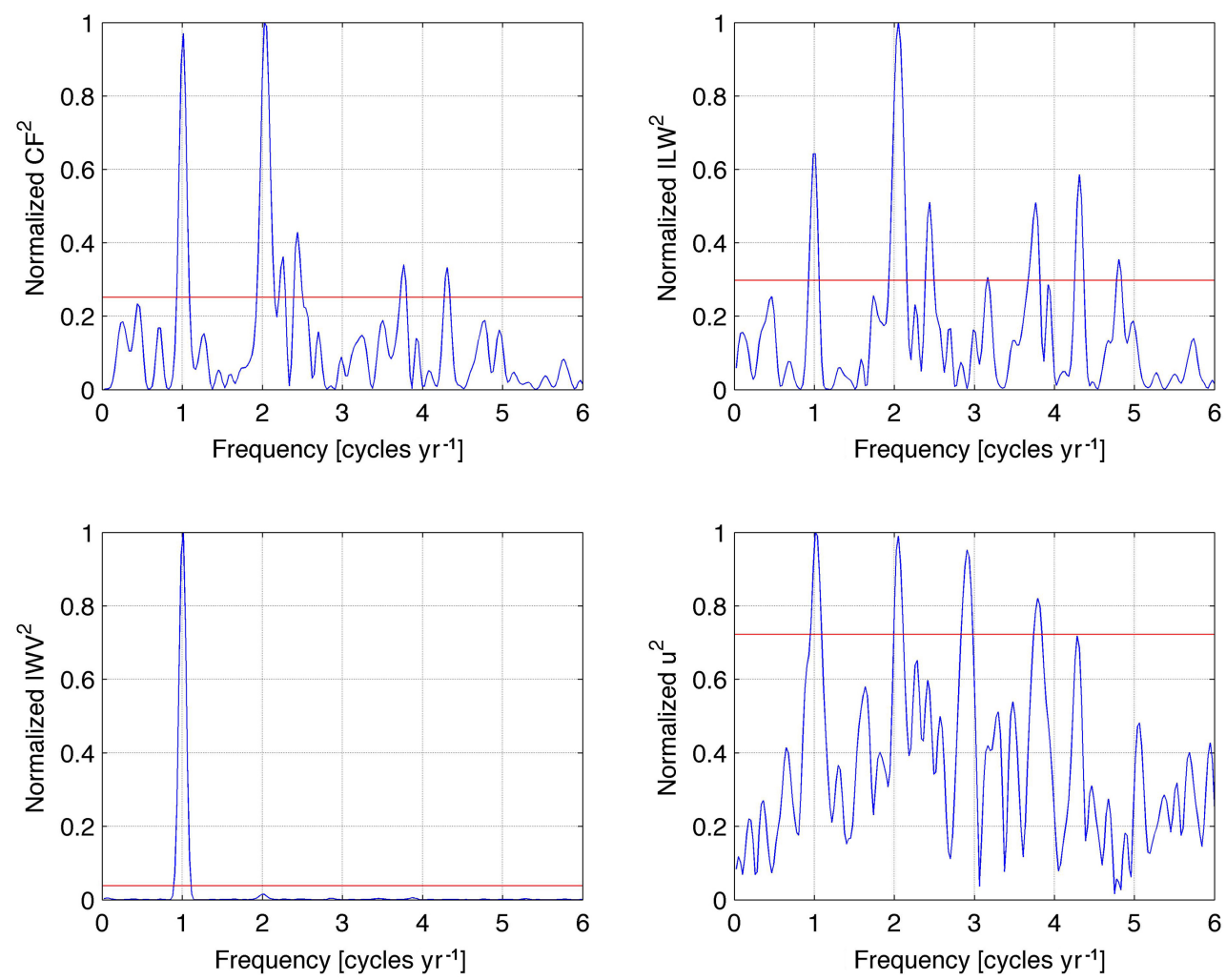

Figure 2. Normalized power spectra of CF, ILW and IWV at Bern for the time interval from January 2004 to November 2016 . In addition we show the normalized power of the zonal wind $u$ from ECMWF operational reanalysis at $830 \mathrm{hPa}(1.5 \mathrm{~km}$ altitude) above Bern and for the same time interval. The red line is the $2 \sigma$ level ( $95 \%$ confidence).

spectrum of lower-tropospheric wind, which is provided by ECMWF operational analyses at the grid point close to Bern. Section 4 presents the climatologies of short-term variability in CF, ILW, IWV and $u$ derived from daily means in the time interval from 2004 to 2016 . We find a weekly cycle for CF and ILW in spite of the relatively clean air above Bern, Switzerland. Conclusions are given in Sect. 5.

\section{Instrument, data and analysis}

\subsection{The microwave radiometer TROWARA}

The study is based on the measurements of TROWARA. TROWARA is a dual-channel microwave radiometer built by Peter and Kämpfer (1992). It provides vertically integrated water vapour and vertically integrated cloud liquid water, also known as liquid water path. TROWARA is located inside a temperature-controlled room on the roof of the EXWI building of the University of Bern $\left(46.95^{\circ} \mathrm{N}, 7.44^{\circ} \mathrm{E}\right.$; $575 \mathrm{~m}$ a.s.1.). Since TROWARA is operated indoors, it is capable to measure IWV even during rainy periods.

The two microwave channels are at $21.4 \mathrm{GHz}$ (bandwidth $100 \mathrm{MHz}$ ) and $31.5 \mathrm{GHz}$ (bandwidth $200 \mathrm{MHz}$ ). The lower frequency is more sensitive to microwaves from wa- ter vapour, and the higher frequency is more sensitive to microwaves from atmospheric liquid water.

The radiative transfer equation of a non-scattering atmosphere is

$T_{\mathrm{B}, i}=T_{\mathrm{c}} e^{-\tau_{i}}+T_{\text {mean }, i}\left(1-e^{-\tau_{i}}\right)$,

where $T_{\mathrm{B}, i}$ is the observed brightness temperature of the $i$ th frequency channel (e.g. $21 \mathrm{GHz}) . \tau_{i}$ is the opacity along the line of sight of the radiometer and $T_{\mathrm{c}}$ is the contribution of the cosmic microwave background. $T_{\text {mean }, i}$ is the effective mean temperature of the troposphere (Ingold et al., 1998; Mätzler and Morland, 2009).

From Eq. (1) we can derive the opacities

$\tau_{i}=-\ln \left(\frac{T_{\mathrm{B}, i}-T_{\text {mean }, i}}{T_{c}-T_{\text {mean }, i}}\right)$,

where the radiances $T_{\mathrm{B}, i}$ are measured by TROWARA.

For a plane-parallel atmosphere, the opacity is closely related to IWV and ILW by a quasi-linear relationship

$\tau_{i}=a_{i}^{\prime \prime}+b_{i}^{\prime \prime} \mathrm{IWV}+c_{i}^{\prime \prime} \mathrm{ILW}$,

where the coefficients $a^{\prime \prime}$ and $b^{\prime \prime}$ are not really constant since they can partly depend on air pressure. Mätzler and Morland 

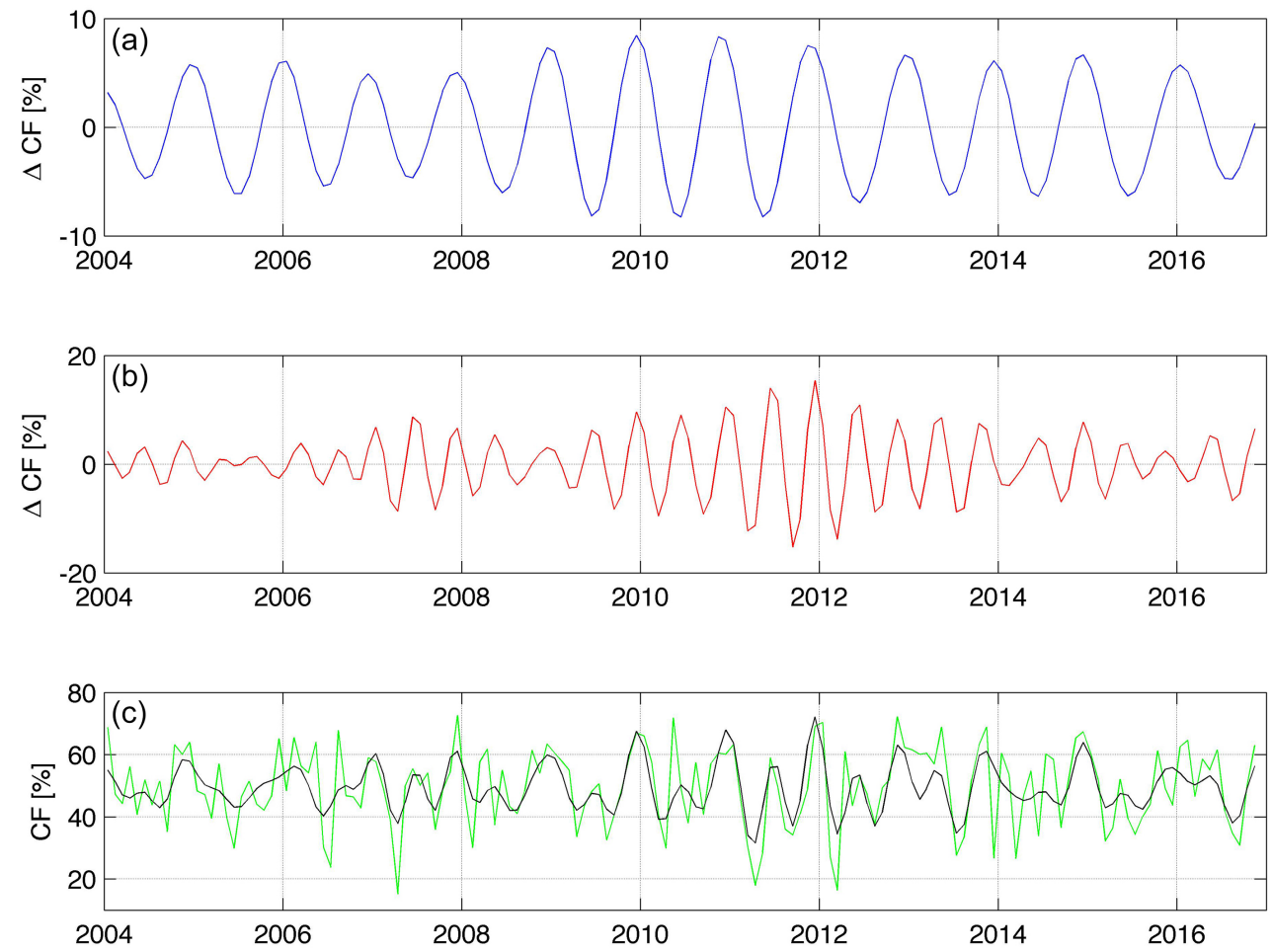

Figure 3. Annual oscillation (a), semiannual oscillation (b) and time series of monthly means of CF (green line in panel c) derived from TROWARA measurements at Bern. The black line is the sum of the annual oscillation, the semiannual oscillation and the total mean of CF.

(2009) show that these coefficients can be statistically derived by means of nearby radiosonde measurements and finetuned in periods with a clear atmosphere. The radiosonde yields the atmospheric profile, which is used for forward modelling of the brightness temperatures and opacities that would have been observed by TROWARA. Further, the radiosonde provides IWV so that the equation set (Eq. 3) can be solved for the coefficients $a^{\prime \prime}$ and $b^{\prime \prime}$ for clear sky (Mätzler and Morland, 2009). The coefficient $c^{\prime \prime}$ is the mass absorption coefficient of cloud water. It depends on temperature (and frequency) but not on pressure. It is derived from the physical expression of Rayleigh absorption by clouds (Mätzler and Morland, 2009). The equation set (Eq. 3) permits the retrieval of IWV and ILW if the opacities are measured at 21 and $31 \mathrm{GHz}$. Thus, a dual-channel microwave radiometer can monitor IWV and ILW with a time resolution of 6-11 s and nearly all-weather capability during day and nighttime.

An infrared radiometer channel is operated at $\lambda=9.5-$ $11.5 \mu \mathrm{m}$, which measures the physical temperature at the cloud base when the cloud is optically thick (ILW > $30 \mathrm{~g} \mathrm{~m}^{-2}$ ). TROWARA's antenna coil has a full width at half power of $4^{\circ}$ and is pointing at the sky at an zenith angle of $50^{\circ}$ towards southeast. The view direction is always constant, and the microwave and infrared channels of TROWARA observe the short-term temporal variations of the brightness temperature in the same volume of the atmosphere. This contributes to the high sensitivity of TROWARA for cloud detec- tion. Further details of the sensors and retrieval technique are given in Cossu et al. (2015) and Mätzler and Morland (2009).

TROWARA has been operated since 1994, and it has delivered an almost uninterrupted time series of ILW since 2004 , with a time resolution of $11 \mathrm{~s}$ until the end of 2009 and $6 \mathrm{~s}$ afterwards. The cloud detection in the line of sight of TROWARA is performed with the same time resolution, and the criterion is that ILW $>3 \sigma_{\text {noise }}=2.3 \mathrm{~g} \mathrm{~m}^{-2}$. Cossu et al. (2015) determined the instrumental noise $\sigma_{\text {noise }}=$ $0.77 \mathrm{~g} \mathrm{~m}^{-2}$ of TROWARA from the noise of ILW during 245 cloud-free days. If a ILW value exceeds the $3 \sigma_{\text {noise }}$ level, then we are $99.7 \%$ confident that the ILW value was generated by a cloud and not by instrumental noise. We emphasize that this is a remarkable sensitivity for a microwave radiometer. Contrary to the ILW series, the time series of IWV have been used since 1994 for trend analyses, as shown by Morland et al. (2009) and Hocke et al. (2011)

Thin liquid water clouds were the focus of the study by Hirsch et al. (2012). They derived the microphysical and optical properties of thin liquid water clouds and emphasized that these clouds should be considered in climate studies since these clouds are frequent and they change the radiative forcing of the climate system. Measurements indicated that the downwelling infrared radiance of a thin liquid water cloud is increased by about $60 \%$ compared to clear sky. Hirsch et al. (2012) reported that thin liquid water cloud ar- 

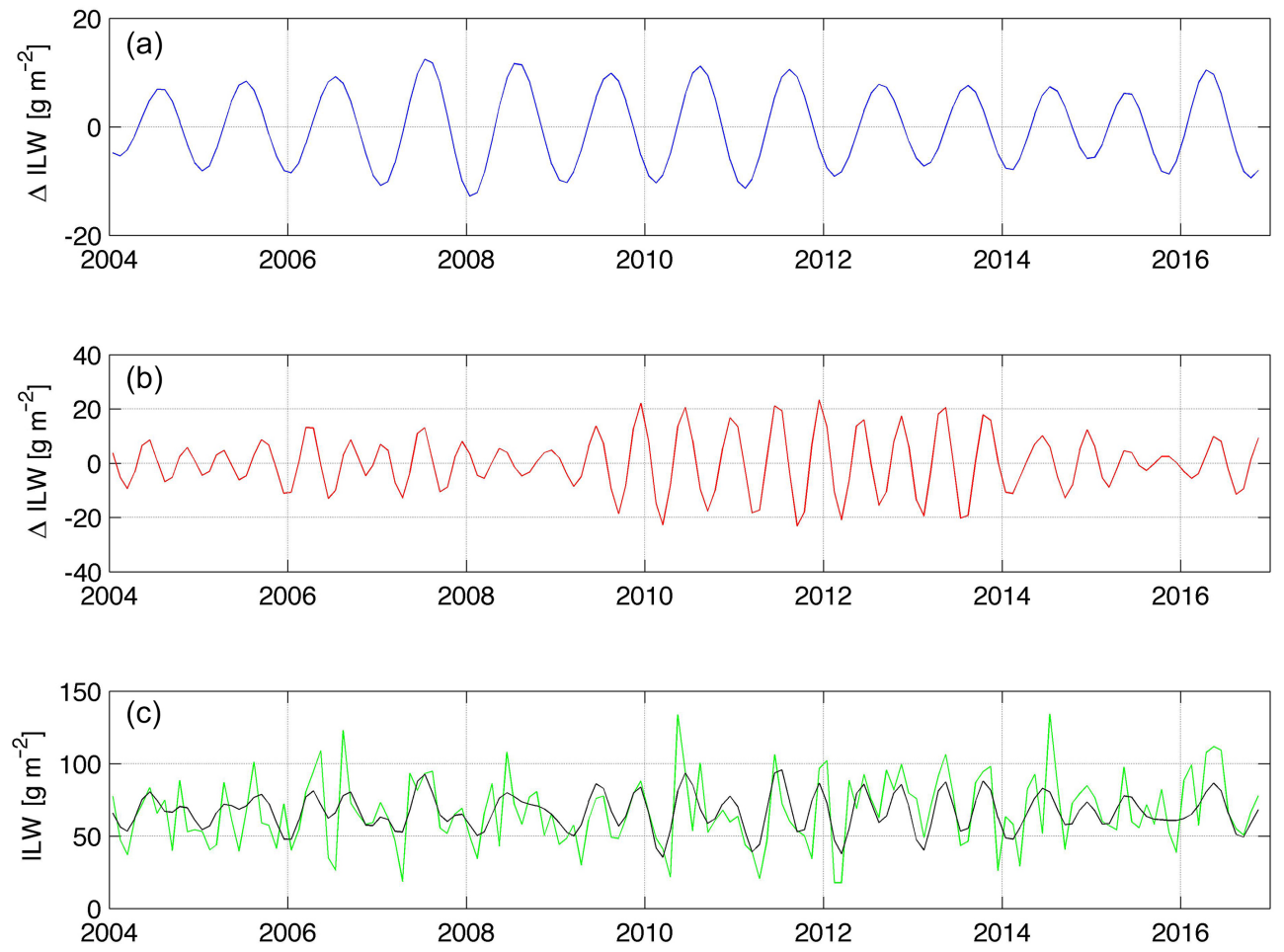

Figure 4. Annual oscillation (a), semiannual oscillation (b) and time series of monthly means of ILW (green line in panel c) derived from TROWARA measurements at Bern. The black line is the sum of the annual oscillation, the semiannual oscillation and the total mean of ILW.

eas are often located at the edges of and in the region between clouds (twilight zone of clouds).

Since TROWARA is not sensitive to ice clouds, CF of TROWARA is in general smaller compared to synoptic observations. Cossu et al. (2015) found a CF difference of about $17 \%$ between TROWARA and synoptic observations in the same region over a period of 6 years. In addition, some of the very thin and tenuous clouds which are still visible by eye might be not seen by TROWARA. Hocke et al. (2016) derived $\mathrm{CF}$ of different classes of liquid water clouds using the TROWARA measurements and performed a trend analysis. In the present study, we only consider the class of all liquid water clouds with ILW $>2.3 \mathrm{~g} \mathrm{~m}^{-2}$. Finally, the CF, ILW and IWV measurements of TROWARA at Bern are within the central basin of the Swiss plateau. In the following, we investigate the monthly means of CF, ILW and IWV, which we derived from the TROWARA data.

\subsection{Data analysis}

$\mathrm{CF}$ was determined in time domain. $\mathrm{CF}$ is the quotient of the time intervals when ILW $>2.3 \mathrm{~g} \mathrm{~m}^{-2}$ and the total observation time. The time intervals are as small as $6 \mathrm{~s}$ for ILW data after 2009 and $11 \mathrm{~s}$ for ILW data before 2009. Thus, we set the cloud flag with a high temporal resolution ( 6 or $11 \mathrm{~s})$, which is required because of the high spatiotemporal variability of clouds floating through the fixed line of sight of TROWARA. Monthly mean of ILW were obtained by averaging of the temporally high-resolution data. An upper threshold of $400 \mathrm{~g} \mathrm{~m}^{-2}$ is used that means in the presence of rain droplets we take the value $400 \mathrm{~g} \mathrm{~m}^{-2}$ as an estimate of the ILW of the cloud droplets. During precipitation intervals TROWARA overestimates ILW of the cloud droplets because of the strong microwave emission from the rain droplets $(d>0.2 \mathrm{~mm})$. This is the reason why we take an upper threshold of $400 \mathrm{~g} \mathrm{~m}^{-2}$ for vertically integrated cloud liquid water path during rainy periods. Monthly means of IWV are well defined because of the continuous monitoring of IWV by TROWARA.

The power spectra are obtained by folding the time series of IWV, ILW or CF with a Hamming window and by applying zero padding at the beginning and end of the time series. After the Fourier transformation, the power spectra are normalized by the power of the strongest spectral component.

The time series of the $\mathrm{AO}$ and the $\mathrm{SAO}$ are derived by means of bandpass filtering. The time series are filtered with a digital non-recursive, finite impulse response bandpass filter performing zero-phase filtering by processing the time series in forward and reverse directions. The number of filter coefficients corresponds to a time window of three times the central period, and a Hamming window has been selected for the filter. Thus, the bandpass filter has a fast response time to temporal changes in the data series. The variable choice of the filter order permits the analysis of wave trains with 

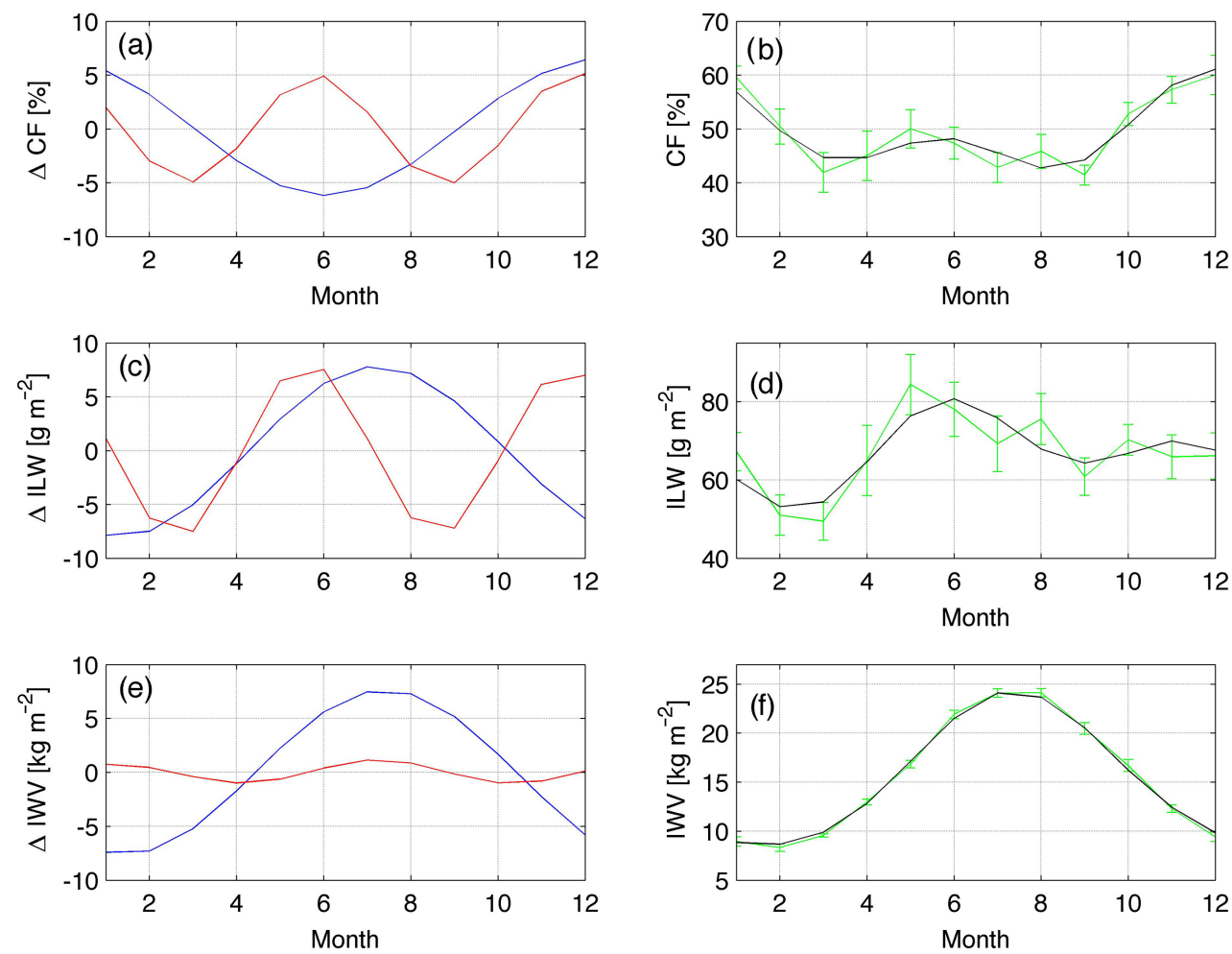

Figure 5. Mean seasonal behaviour of annual oscillation (blue), semiannual oscillation (red), monthly means (green) and the sum of AO and SAO (black) derived from TROWARA measurements of the time interval 2004 to 2016. The top panels (a) and (b) are for CF, the middle panels (c) and (d) are for ILW and the bottom panels (e) and (f) are for IWV. The standard error of the mean is given by green error bars.

a resolution that matches their scale. The bandpass cut-off frequencies are at $f_{\mathrm{c}}=f_{p} \pm 10 \% f_{p}$, where $f_{p}$ is the central frequency. More details about the bandpass filtering are given by Studer et al. (2012).

The mean seasonal behaviour of the time series is obtained by sorting the data for the month and taking the mean and the standard error of the mean.

\section{Long-term oscillations in atmospheric water with periods $>60$ days}

The time series of CF, ILW and IWV are shown in Fig. 1. The green line corresponds to the monthly means while the red line is the 12-month moving average. The blue lines denote the standard deviations of the parameter for an interval of 12 months. The annual cycle is only clear for the IWV series in the lower panel. The interannual variations (red line) of CF and ILW are quite similar. The seasonal variations of CF and ILW are rather unclear. A spectral analysis of the monthly mean series gives us more information.

Figure 2 shows the normalized power spectra of the monthly mean series of CF, ILW, IWV and $u$. The horizontal red lines denote the $2 \sigma$ level, where the confidence is $95 \%$. The power spectrum of IWV is simple. IWV has only one dominant AO. The power spectra of CF and ILW resem-

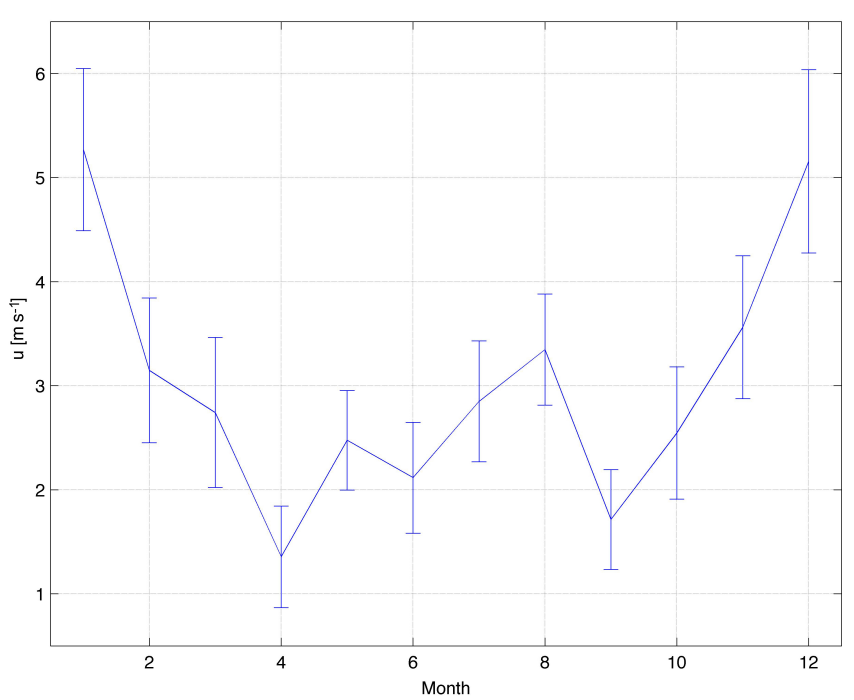

Figure 6. Mean seasonal behaviour of zonal wind $u$ from ECMWF operational reanalysis at $830 \mathrm{hPa}(1.5 \mathrm{~km}$ altitude $)$ above Bern. The standard error of the mean is given by error bars.

ble each other to some extent. The SAO is approximately of the same size as the AO in the case of CF, ILW and the zonal wind $u$. Further, there are statistically significant spec- 

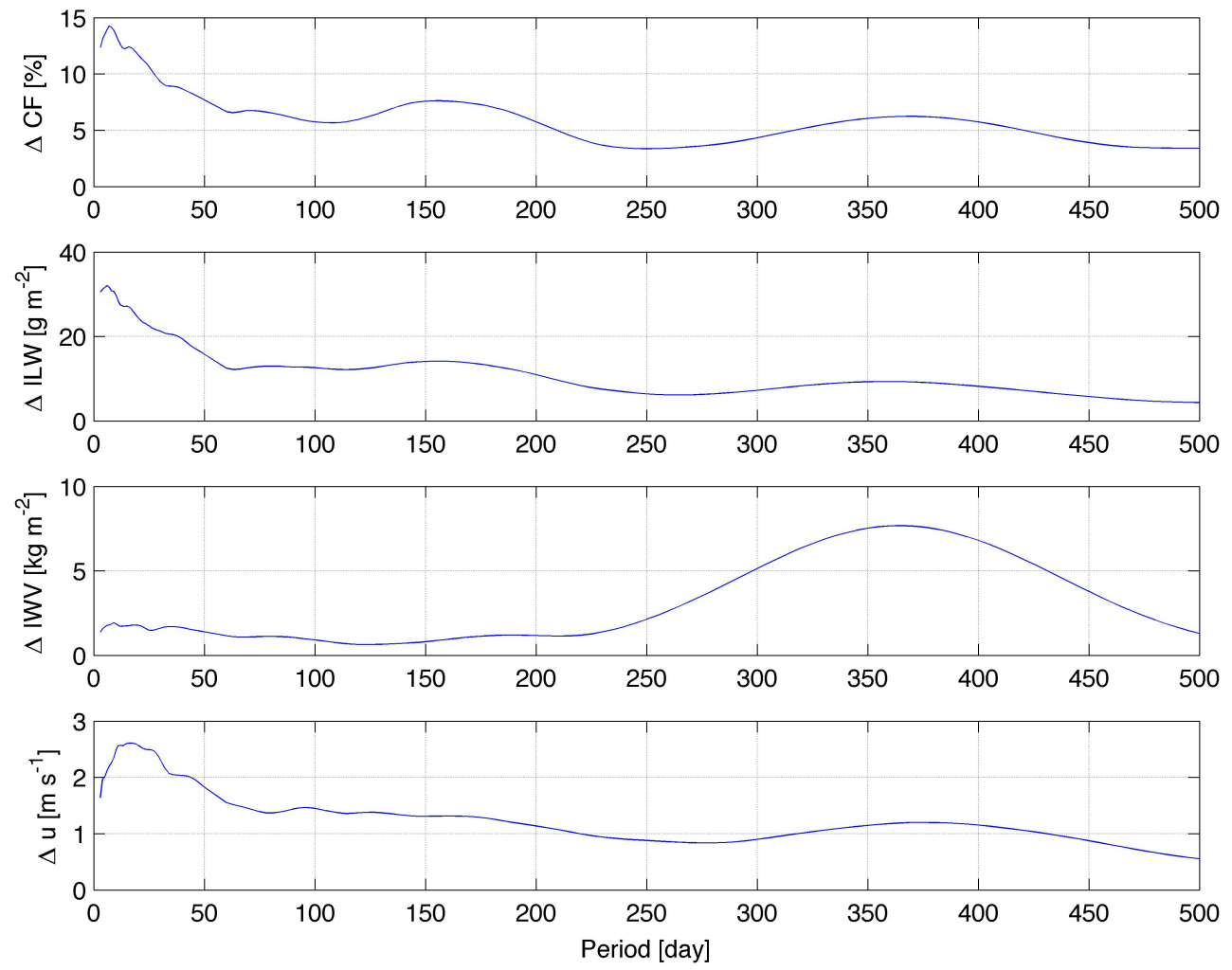

Figure 7. Mean amplitude spectra of CF, ILW and IWV from TROWARA at Bern for the time interval from January 2004 to November 2016. In addition, we show the coincident amplitude spectrum of zonal wind $u$ from ECMWF operational reanalysis at $830 \mathrm{hPa}(1.5 \mathrm{~km}$ altitude) above Bern. The amplitude is determined by a bandpass filter with a fast response time.

tral components with periods of $76,85,97$ and 150 days. However, the component at 150 days only occurs in CF and ILW. For the interpretation of the CF and ILW spectra we add a power spectrum of the zonal wind at $830 \mathrm{hPa}$ (ca. $1.5 \mathrm{~km}$ altitude). The zonal wind series originates from ECMWF operational reanalysis at the grid point nearest to Bern $\left(46.95^{\circ} \mathrm{N}\right.$, $7.44^{\circ} \mathrm{E}$ ). It is surprising that the power spectrum of the zonal wind has strong annual harmonics that reach up to the fourth harmonic. Actually, one would assume only an AO in the prevailing westerly wind at northern midlatitudes that is larger during the winter than during the summer. The cyclones and anticyclones embedded in the westerly mean flow would be expected to have a random nature, which would produce white noise in the spectrum. However, the $u$ spectrum in Fig. 2 shows that there is an harmonic order in the temporal $u$ fluctuations favouring the occurrence of annual harmonics up to the fourth order. The harmonics may result from an interaction between the $\mathrm{AO}$ and intra-seasonal oscillations where the latter could be connected to synoptic-scale variations or synoptic weather types.

Since lower-tropospheric wind is a major player for cloud formation and transport processes, we suggest that the spectral components in the zonal wind spectrum could be one cause for the annual and semiannual oscillations in the power spectra of CF and ILW. In addition, the periodicities of 97 and 85 days (close to the fourth harmonic) are strong in the spectra of $u, C F$ and ILW. However, cloud formation also depends on synoptic weather types which often have a seasonal dependence. For example, the situation of a flat-pressure gradient weather type (or convective indifferent type) in western and central Europe is typical for summer, when convective forcing is often larger than advective forcing above Switzerland (Schlemmer et al., 2011; Collaud Coen et al., 2011; MeteoSwiss, 2015). The high evaporation rate during summer also supports that a moist atmosphere is getting unstable, and a diurnal convection cycle leads to cumuliform clouds in the afternoon and evening hours (Schlemmer et al., 2011; MeteoSwiss, 2015).

During winter, the Swiss plateau often has low stratus which develops from condensation of atmospheric water vapour near to the cold Earth surface. Turbulence spreads the fog or cloud droplets up to the inversion layer in about $1.5 \mathrm{~km}$ altitude. Scherrer and Appenzeller (2014) reported that 6-8 days per month in the Swiss plateau during winter have fog and stratus over an half day or more (e.g. low stratus before noon). Stratus in the Swiss plateau during winter is often associated with a cold wind from the northeast, which is called the bise (MeteoSwiss, 2015). Collaud Coen 

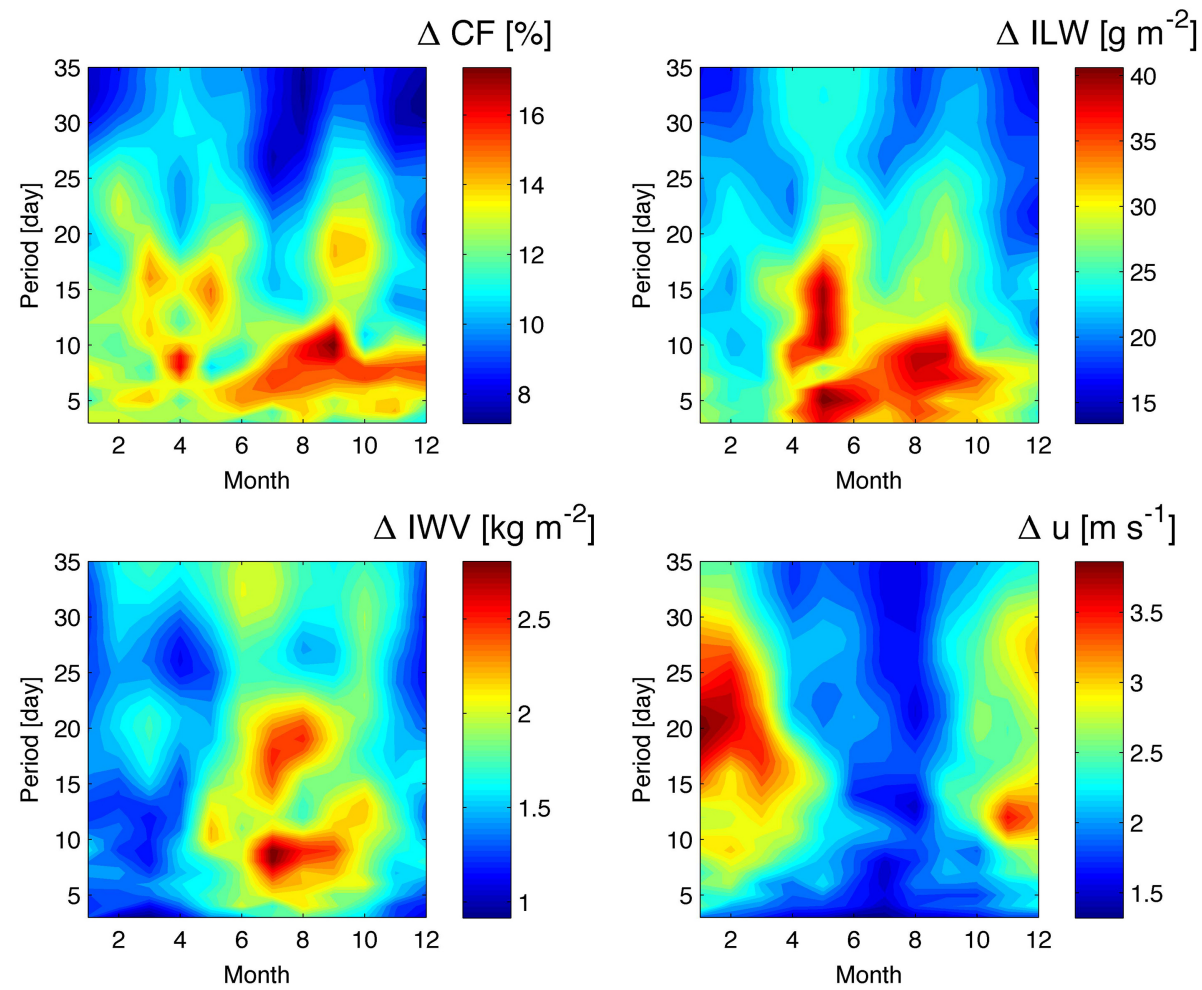

Figure 8. Climatologies of the short-term variability of CF, ILW and IWV from TROWARA at Bern for the time interval from January 2004 to November 2016. In addition, we show the coincident climatology of zonal wind $u$ from ECMWF operational reanalysis at $830 \mathrm{hPa}(1.5 \mathrm{~km}$ altitude) above Bern.

et al. (2011) reported that there is also a seasonal cycle of the advective weather types with an occurrence rate of about $45-50 \%$ during winter and about $20 \%$ in summer. Particularly, the warm and cold fronts of cyclones pass Switzerland, where the rising air masses at the warm front induce middle and high-level clouds. Further the north and the south foehn can be associated with cloud formation over the Swiss plateau. The occurrence of foehn is decreased during summer (Collaud Coen et al., 2011). Thus, the enhancement of cloud fraction by low stratus and advective weather types in winter and cumuliform clouds in summer may induce a SAO in CF and ILW over Bern.

Figure 3 shows the 12-month bandpass-filtered series of $\mathrm{CF}$ in the upper panel, which corresponds to the AO. The amplitude of the AO was strongest around 2010 to 2011. The middle panel shows the SAO, which is obtained by means of a 6-month bandpass filter. The $\mathrm{SAO}$ is strong from 2010 to 2014. The lower panel shows the combination of the $\mathrm{AO}$ and SAO (black line), which fits well to the unfiltered green line of the monthly means of CF. Figure 4 shows the bandpass-filtered AO and SAO for the parameter ILW. Similar to CF, the SAO in ILW is strong from 2010 to 2014. The lower panel shows the combination of the AO and SAO (black line), which fits well to the unfiltered green line of the monthly means of ILW. A relationship between CF and ILW is expected since $\mathrm{CF}=0$ if ILW $<2.3 \mathrm{~g} \mathrm{~m}^{-2}$. An interannual change of the occurrence rate of certain weather types could explain the interannual variation of the SAO. For example, an enhancement in the occurrence of cumuliform clouds in the summers from 2010 to 2014 may lead to the enhanced SAO from 2010 to 2014. In future, the automated cloud type classification by thermal infrared cameras may provide objective time series of cloud type frequencies.

Figure 5 depicts the climatologies of CF, ILW and IWV averaged over the time interval from 2004 to 2016. The lefthand-side panels show the mean AO (blue) and the mean $\mathrm{SAO}$ (red). It is surprising that the $\mathrm{AO}$ of $\mathrm{CF}$ is almost in anti-phase to the AO in ILW, which peaks in July. We think that convective cumuliform clouds are responsible for the high ILW values in June and July since cumuliform clouds are typical for the flat-pressure gradient situation, which has an occurrence frequency of about $35-40 \%$ in summer (Collaud Coen et al., 2011; MeteoSwiss, 2015). The right-handside panels show the mean behaviour of the combined AO and SAO in black while the green lines show the mean behaviour derived from the monthly mean series of CF, ILW and IWV. In addition, the standard error of the mean is given by green error bars. We can see that the AO and the SAO component fit a major part of the observed monthly mean series. There are only a few month-to-month variations in the 

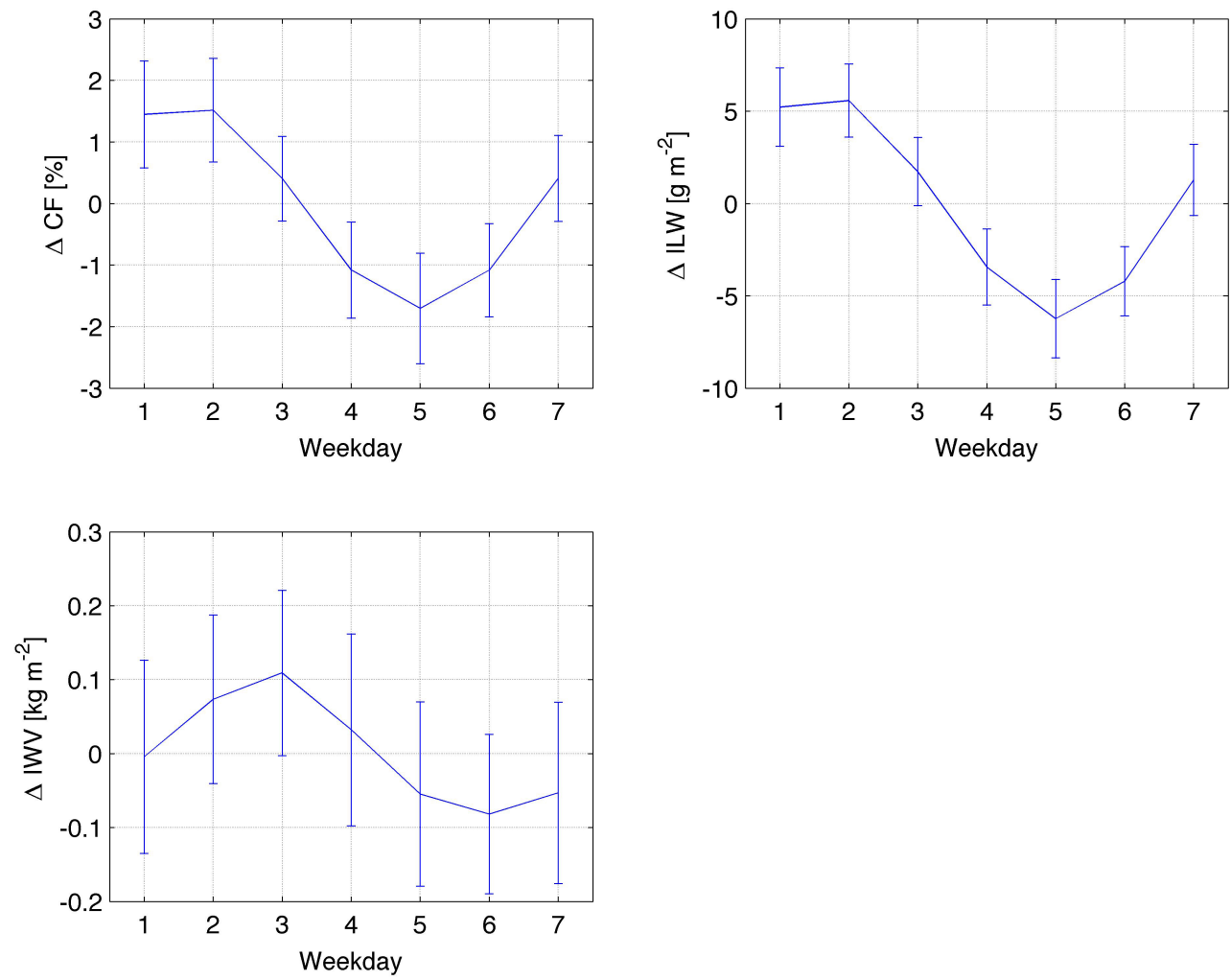

Figure 9. Weekly cycle of CF, ILW and IWV at Bern for the June to September observations of TROWARA during the time interval from January 2004 to November 2016. Weekday 1 corresponds to Sunday, weekday 2 corresponds to Monday, and so on. The vertical lines indicate the error of the mean of the averaged values.

climatology of monthly means (green curve), which are not approximated by the combined AO and SAO (black curve).

Figure 6 shows the climatology of eastward wind at $830 \mathrm{hPa}(1.5 \mathrm{~km})$ above Bern over the time from 2004 to 2016. It is obvious that the climatology of $u$ is rather similar to the climatology of CF in Fig. 5. It seems that the strong eastward wind in December and January is associated with the advective weather type which generates middle and high clouds over Switzerland in the warm zone and the warm front of cyclones (MeteoSwiss, 2015). Related to the study of Nuijens and Stevens (2012), we argue that an increase in the lower-tropospheric wind $u$ leads to a deepening of the cloud layer. In addition, one may argue that an eastward advection of moist air from the Atlantic towards the Swiss plateau and the Alps occurs, which leads to a maximum of $\mathrm{CF}$ in winter. The so-called advective west weather type is enhanced by about $10 \%$ during winter compared to summer (Collaud Coen et al., 2011). Generally the sum of the advective weather types has an occurrence rate of about $45-50 \%$ during winter and below $25 \%$ during summer (Collaud Coen et al., 2011). Further, there is frequently low stratus in the Swiss plateau in winter that is often connected with the advective northeast weather type (bise) and the cold Earth surface.

\section{Short-term oscillations in atmospheric water with periods $<60$ days}

For the investigation of the short-term variability, we change from the time series of monthly means to the time series of daily means. It can be assumed that the short-term oscillations with periods of a few days to weeks only persist over time intervals of three wave cycles. Thus a Fourier transform over the time interval from 2004 to 2016 is not adequate to address the role of the short-term variability. Instead, we determine the mean amplitudes with a bandpass filter with a fast response time. As described in the data analysis section, the number of filter coefficients corresponds to each central frequency to a time interval of three wave cycles. Thus shortterm variations existing over a short time interval contribute to the mean amplitude spectra, which are shown in Fig. 7. The amplitude spectra of CF, ILW, IWV and $u$ at Bern are derived by the wavelet-like bandpass filter method for the time interval from 2004 to 2016. Again, $u$ originates from operational ECMWF reanalysis at $830 \mathrm{hPa}(1.5 \mathrm{~km})$ above Bern. The spectra of CF, ILW and $u$ are dominated by short-term variability on timescales less than 50 days. The amplitude maxima are at a period of 7 days for CF, 6 days for ILW, 365 days for IWV and 17 days for $u$. 
The bandpass-filtered data sets are also appropriate for the derivation of the climatologies of CF, ILW, IWV and $u$. Figure 8 depicts the mean amplitudes as function of the month and the period. The climatologies of CF, ILW and IWV show some similarities with increased amplitudes in the period range 5-10 days from spring to fall. The climatology of the $u$ spectrum shows a 20-day oscillation in winter which is possibly related to a Rossby wave. The 20 -day period is close to 16 days, which is a theoretical period of a normal mode of a free Rossby wave with a westward-propagating zonal wavenumber 1 (Sassi et al., 2012). However, it is evident that the climatology of the $u$ spectrum cannot explain the 7-day oscillation of CF, ILW and IWV during summer. This indicates that advective forcing is not the reason for the 7day oscillation in summer. The 7-day oscillation could be a man-induced effect that may be enabled by periodic human activities during flat-pressure gradient situations which prevail during summer (Collaud Coen et al., 2011). The synoptic motion of the flat-pressure gradient weather type is dominated by small-scale circulations.

We investigate whether the 7-day oscillation is phaselocked to a weekly cycle which is found in aerosol concentration as induced by manmade air pollution (Gong et al., 2007). In the following, we only consider the data from 1 June to 30 September when the 7-day oscillation is strong. Figure 9 shows a significant weekly cycle for CF and ILW, while the weekly cycle in IWV is marginal. The weekly cycles in CF and ILW have the largest values on Sunday (day 1) and Monday (day 2) while the smallest values occur on Thursday (day 5). It remains unclear whether the observed weekly cycles in CF and ILW are due to manmade air pollution. Barmet et al. (2009) found a well-pronounced and statistical significant weekly cycle for particulate matter above Switzerland but they did not find a statistically significant weekly cycle for precipitation.

\section{Summary}

TROWARA continuously measured CF, ILW and IWV in Bern, Switzerland, from 2004 to 2016. We find indications for interannual variations of CF and ILW. Fourier transformation and bandpass filtering give the result that IWV is dominated by an annual oscillation, leading to an IWV maximum of $24 \mathrm{~kg} \mathrm{~m}^{-2}$ in July to August. The seasonal behaviour of $\mathrm{CF}$ and ILW is composed by both the annual and the semiannual oscillation. However, the $\mathrm{AO}$ of $\mathrm{CF}$ has a maximum in December while the AO of ILW has a maximum in July. The SAO of CF and ILW is strong from 2010 to 2014. We suggest that the SAO could be related to the occurrence frequency of certain weather types that lead, for example, to low stratus in winter and cumuliform clouds in summer. In the future, we expect that automated cloud classification by thermal infrared cameras will give us climatologies of cloud types, which could be helpful for interpretation of the periodicities in CF and ILW.

The normalized power spectra of ILW and CF show statistically significant spectral components with periods of 76 , 85,97 and 150 days. We find a similarity between the power spectra of ILW and CF with those of zonal wind at $830 \mathrm{hPa}$ $(1.5 \mathrm{~km})$ above Bern. The occurrence of higher harmonics in the CF and ILW spectra is possibly forced by the behaviour of the lower-tropospheric wind and the occurrence rate of weather types. This observational result emphasizes the role of the lower-tropospheric wind for generation and transport of clouds over the Swiss plateau. The climatology of CF shows a maximum in winter when the eastward wind is maximal. The mean amplitude spectra of CF, ILW and $u$ are dominated by short-term variability on timescales less than 50 days. The short-term variability of CF, ILW and IWV has increased amplitudes from spring to fall. We find weekly cycles in CF and ILW for summer data (1 June to 30 September). The weekly cycles have largest values on Sunday and Monday. This result is consistent with Stjern (2011), who found that the weekly cycles of cloud amount and the frequency of light precipitation events are dominated by midweek decreases and weekend maxima during summer. In contrast to this observational result, Albrecht (1989) argued that increases in aerosol concentrations may increase the amount of low-level cloudiness through a reduction in drizzle. The relevant mechanisms which lead to the observed weekly cycles in CF and ILW at Bern remain unclear.

Code and data availability. Routines for data analysis and visualization are available upon request by Klemens Hocke. Hourly measurements of IWV and ILW from the radiometer TROWARA are available at the data centre STARTWAVE (http://www.startwave. org) of University of Bern. Six-second data of IWV, ILW and CF are available upon request by Klemens Hocke. We thank the European Centre for Medium-range Weather Forecast (ECMWF) for operational reanalysis data of zonal wind above Bern.

Author contributions. KH carried out the spectral analysis. FNG and $\mathrm{CM}$ took care on the radiometer. All authors contributed to the interpretation of the data set.

Competing interests. The authors declare that they have no conflict of interest.

Acknowledgements. The study was supported by Swiss National Science Foundation under grant number 200021-165516. We thank the reviewers for their valuable and helpful comments.

Edited by: Martina Krämer

Reviewed by: two anonymous referees 


\section{References}

Albrecht, B. A.: Aerosols, Cloud Microphysics, and Fractional Cloudiness, Science, 245, 1227-1230, https://doi.org/10.1126/science.245.4923.1227, 1989.

Barmet, P., Kuster, T., Muhlbauer, A., and Lohmann, U.: Weekly cycle in particulate matter versus weekly cycle in precipitation over Switzerland, J. Geophys. Res.-Atmos., 114, D05206, https://doi.org/10.1029/2008JD011192, 2009.

Beesley, J. A. and Moritz, R. E.: Toward an Explanation of the Annual Cycle of Cloudiness over the Arctic Ocean, J. Climate, 12, 395-415, https://doi.org/10.1175/15200442(1999)012<0395:TAEOTA >2.0.CO;2, 1999.

Bromwich, D. H., Nicolas, J. P., Hines, K. M., Kay, J. E., Key, E. L., Lazzara, M. A., Lubin, D., McFarquhar, G. M., Gorodetskaya, I. V., Grosvenor, D. P., Lachlan-Cope, T., and van Lipzig, N. P. M.: Tropospheric clouds in Antarctica, Rev. Geophys., 50, RG1004, https://doi.org/10.1029/2011RG000363, 2012.

Collaud Coen, M., Weingartner, E., Furger, M., Nyeki, S., Prévôt, A. S. H., Steinbacher, M., and Baltensperger, U.: Aerosol climatology and planetary boundary influence at the Jungfraujoch analyzed by synoptic weather types, Atmos. Chem. Phys., 11, 5931-5944, https://doi.org/10.5194/acp-11-5931-2011, 2011.

Cossu, F., Hocke, K., and Mätzler, C.: A 10-Year Cloud Fraction Climatology of Liquid Water Clouds over Bern Observed by a Ground-Based Microwave Radiometer, Remote Sensing, 7, 7768-7784, 2015.

Gong, D.-Y., Ho, C.-H., Chen, D., Qian, Y., Choi, Y.-S., and Kim, J.: Weekly cycle of aerosol-meteorology interaction over China, J. Geophys. Res.-Atmos., 112, D22202, https://doi.org/10.1029/2007JD008888, 2007.

Hirsch, E., Agassi, E., and Koren, I.: Determination of optical and microphysical properties of thin warm clouds using ground based hyper-spectral analysis, Atmos. Meas. Tech., 5, 851-871, https://doi.org/10.5194/amt-5-851-2012, 2012.

Hocke, K., Kämpfer, N., Gerber, C., and Mätzler, C.: A complete long-term series of integrated water vapour from ground-based microwave radiometers, Int. J. Remote Sens., 32, 751-765, 2011.

Hocke, K., Navas Guzmán, F., Cossu, F., and Mätzler, C.: Cloud Fraction of Liquid Water Clouds above Switzerland over the Last 12 Years, Climate, 4, 48, https://doi.org/10.3390/cli4040048, 2016.

Ingold, T., Peter, R., and Kämpfer, N.: Weighted mean tropospheric temperature and transmittance determination at millimeter-wave frequencies for ground-based applications, Radio Sci., 33, 905918, 1998.

Massons, J., Domingo, D., and Lorente, J.: Seasonal cycle of cloud cover analyzed using Meteosat images, Ann. Geophys., 16, 331341, https://doi.org/10.1007/s00585-998-0331-3, 1998.

Mätzler, C. and Morland, J.: Refined Physical Retrieval of Integrated Water Vapor and Cloud Liquid for Microwave Radiometer Data, IEEE T. Geosci. Remote, 47, 1585-1594, 2009.

Meehl, G. A., Hurrell, J. W., and Loon, H. V.: A modulation of the mechanism of the semiannual oscillation in the Southern Hemisphere, Tellus A, 50, 442-450, https://doi.org/10.3402/tellusa.v50i4.14537, 1998.
MeteoSwiss: Typische Wetterlagen im Alpenraum, Report of Bundesamt für Meteorologie und Klimatologie MeteoSchweiz, 1-28, http://www.meteoswiss.admin.ch/content/ dam/meteoswiss/de/service-und-publikationen/Publikationen/ doc/Web_Wetterlagen_DE_low.pdf (last access: 11 October 2017), 2015.

Morland, J., Collaud Coen, M., Hocke, K., Jeannet, P., and Mätzler, C.: Tropospheric water vapour above Switzerland over the last 12 years, Atmos. Chem. Phys., 9, 5975-5988, https://doi.org/10.5194/acp-9-5975-2009, 2009.

Nuijens, L. and Stevens, B.: The Influence of Wind Speed on Shallow Marine Cumulus Convection, J. Atmos. Sci., 69, 168-184, https://doi.org/10.1175/JAS-D-11-02.1, 2012.

Peter, R. and Kämpfer, N.: Radiometric Determination of WaterVapor and Liquid Water and Its Validation with Other Techniques, J. Geophys. Res.-Atmos., 97, 18173-18183, 1992.

Sassi, F., Garcia, R. R., and Hoppel, K. W.: Large-Scale Rossby Normal Modes during Some Recent Northern Hemisphere Winters, J. Atmos. Sci., 69, 820-839, https://doi.org/10.1175/JAS-D11-0103.1, 2012.

Scherrer, S. C. and Appenzeller, C.: Fog and low stratus over the Swiss Plateau - a climatological study, Int. J. Climatol., 34, 678686, https://doi.org/10.1002/joc.3714, 2014.

Schlemmer, L., Hohenegger, C., Schmidli, J., Bretherton, C. S., and Schär, C.: An Idealized Cloud-Resolving Framework for the Study of Midlatitude Diurnal Convection over Land, J. Atmos. Sci., 68, 1041-1057, https://doi.org/10.1175/2010JAS3640.1, 2011.

Stjern, C. W.: Weekly cycles in precipitation and other meteorological variables in a polluted region of Europe, Atmos. Chem. Phys., 11, 4095-4104, https://doi.org/10.5194/acp-114095-2011, 2011.

Studer, S., Hocke, K., and Kämpfer, N.: Intraseasonal oscillations of stratospheric ozone above Switzerland, J. Atmos. Sol.-Terr. Phy., 74, 189-198, 2012.

van den Broeke, M.: The semi-annual oscillation and Antarctic climate. Part 3: the role of nearsurface wind speed and cloudiness, Int. J. Climatol., 20, 117-130, https://doi.org/10.1002/(SICI)10970088(200002)20:2<117::AID-JOC481>3.0.CO;2-B, 2000.

Verlinden, K. L., Thompson, D. W. J., and Stephens, G. L.: The Three-Dimensional Distribution of Clouds over the Southern Hemisphere High Latitudes, J. Climate, 24, 5799-5811, https://doi.org/10.1175/2011JCLI3922.1, 2011. 